\title{
Pathogenic Effect of Trichoderma Asperelliodes on Aphis Craccivora
}

\author{
A.A.Khattab ${ }^{1}$, T.I.El-Sayed ${ }^{1}$, M.S.Hashem ${ }^{2}$ and S.A.Ibrahiem ${ }^{2}$ \\ ${ }^{1}$ Botany Dept., Faculty of Science, Benha Univ., Benha, Egypt \\ ${ }^{2}$ Plant Protection Research Institute, Sharkia, Egypt \\ E-Mail:Sohilaahmed2421987@gmail.com
}

\begin{abstract}
The search for new microbial agents for pest control is one of the most important goals in the field of biological control. Some fungal species showed insecticidal activities. Therefore, isolation of more local fungal strains that would be more adapted to the local pest hosts and possesses greater insecticidal activities will be of great value. Studies were carried out in Plant Protection Research Institute, Sharkia branch, Sharkia governorate, Egypt during the period of 2014 to 2015 to survey aphids on some legumes. Trichoderma asperelliodes was isolated from soil, seeds and aphid insects, and was identified morphologically by light microscope and genetically using 18-S ribosomal DNA. Effect of different $\mathrm{pH}$ values $(5.5,6.5,7,7.5$ and 8.5$)$ and temperatures $\left(20,23,25,27,30,35\right.$ and $\left.40{ }^{\circ} \mathrm{C}\right)$ on T. asperelliodes mycelial growth rates and activity were also studied. The toxicity of $T$. asperelliodes spore suspension on Aphis craccivora under laboratory condition was examined under electron microscopes (SEM and TEM). The results showed that the optimum environmental conditions for mycelial growth rates of $T$. asperelliodes were at $30^{\circ} \mathrm{C}$ and $\mathrm{pH} 7.5$. Also, T. asperelliodes has a significant effect in controlling legume aphids with $\mathrm{LC}_{50}$ value of $5.4 \times 10^{7}$ spores $\mathrm{ml}^{-1}$ and $\mathrm{LT}_{50}$ value of 5.1 days.
\end{abstract}

Keywords: Trichoderma asperelliodes, Biocontrol, Aphis craccivora.

\section{Introduction}

Aphides (Homoptera) are one of the most important groups of insect pests in the world. To date, about 4000 aphid species have been described and about 250 species are serious pests to various crops around the world.

Aphids develop at prodigious rate by parthenogenesis and have an efficient dispersal strategy. Their feeding on phloem sap cause stunting, discolora-tion and deformation of plants.

Aphids are major vectors of plant viruses. Although many products belonging to existing insecticide groups are effective against aphids, resistance to insecticides that have long history of use is a serious problem to farmers and the environment, beneficial insects and natural enemies [1].

Due to high cost of protecting crops from these pests with chemical pesticides, the increasing resistance to many chemical pesticides $[2,3]$ and reduction of the main predator populations [4\&5] which are responsible for killing high proportion of egg and larvae of cotton bollworms through the season [6].

Pest control is a key component of various strategies aimed at preventing the spread of pests in order to increase food production. Nearly all pest control prog-rams depend on the use of chemical insecticides formulated as direct contact sprays or dusts.

The commercially available chemical pesticides in modern agriculture are under pressure to be removed from the market because of their hazardous impact on the natural environment. To face this problem, biological control agents, which include effective microorganisms and microbial metabolites products, have long been attracting attention as alternatives to chemical agents [7].

A control program based on selective materials, which would allow survival of beneficial species and cause the mortality of destructive ones, is desirable. The uses of bacterial pathogens with known insecticide activity as microbial insecticide are speciesspecific, and that makes it harmless to non-target organisms and to the environment [8] Wellknown fungal agents which have been used successfully for insect control are Trichoderma species.

Aphids are attacked by numerous entomopatho-genic fungi $[9,10]$. So, the search for new microbial agents for pest control is one of the most pressing needs in the field of biological control.

Therefore, isolation and scanning of more local fungal strains that would be more adapted to the local pest hosts and possesses greater insecticidal activities or broader host range is important for biological control ${ }^{\text {(11). }}$

The main objectives of this study were to isolate and explore the usage of Trichoderma asperelliodes as a biological control agent to leguminous aphid insects and detect the optimal environmental conditions for its growth and higher activity.

\section{Materials and methods}

\section{Aphid insects Survey}

Survey studies were carried out on Cowpea and Beans crops farms located in Meniat ElKamh city, Sharkia governorate, Egypt during 2014 and 2015 to survey Aphid insects. The 
farms received normal agricultural practices and no chemical control was applied. For sampling, twenty five leaves were picked up randomly once a weak from each farm and for all districts. The samples were put in polyethylene bags and transferred to the laboratory for carefully inspection. These samples were examined in the same day by using stereomicroscope.

\section{Isolation, purification and identification of Trichoderma asperelliodes}

Trichoderma asperelloides was isolated from soil; seeds and insects at modified spasific Czapek-Dox's agar media containing $1.0 \%$ colloidal chitin as a carbon source [12-14]. The isolated fungal species was purified and identified morphologically by light microscope and genetically was identified according to molecular biological method by $18 \mathrm{~S} \mathrm{r}$ RNA gene of DNA (15) at colors-lab, Cairo, Egypt and it was also kindly confirmed by Plant Pathology Research Institute, Agricultural Research Center, Cairo, Egypt. The fungal isolates were descendant of pure single slant culture.

The stock culture of the isolated fungal species were maintained on Czapek-Dox's agar slants then stored at 40C and renewed at monthly intervals [16].
2.1 Molecular characterization (sequence of $18 S$ rRNA gene of DNA)

Molecular characterization involved the following steps according to the protocol [15].

\subsubsection{Extraction of DNA by protocol of Gene} jet genomic DNA purification Kit (Thermo)

The procedure of DNA extraction was applied according to the manufacture Manual. Maxima ${ }^{\circledR}$ hot start PCR master mix (2X) was gently mixed by Vortexing and briefly centrifuged after thawing.

- The samples were gently mixed by vortexing and spun down.

- PCR was performed the recommended thermal cycling conditions

- After that, four $\mu \mathrm{L}$ from the PCR mixture were added to examine the PCR product on $1 \%$ agarose gel against $1 \mathrm{~Kb}$ plus ladder (fermentas).

\subsubsection{PCR cleans up of the PCR product using GeneJet ${ }^{T M}$ PCR Purification Kit (Thermo)}

Sequencing was performed by using Big Dye terminator cycle sequencing kit (Applied BioSystems, USA). Sequen-cing products were resolved on an Applied Biosystems model 3730XL automated DNA sequencing system (Applied Bio-Systems, USA). Trichoderma asperell-oides (Hypocrea asperelloides)

\section{ITS 1}

ITS4

\section{(TCC GTA GGT GAA CCT GGGG)} (TCC TCC GCT TAT TGA TAT GC)

\section{Effect of environmental conditions ( $\mathrm{pH}$ and temperature) on the rate of mycelial growth and activity of Trichoderma asperelliodes}

\subsection{Effect of pH values}

In this experiment, flasks with the same amount of modified Czapek-Dox's broth media $(50 \mathrm{ml})$ containing $1.0 \%$ colloidal chitin as a carbon source was adjusted to the following $\mathrm{pH}$ values $5.5,6.5,7,7.5$ and 8.5 by addition of varying amounts of $1 \mathrm{~N} \mathrm{HCl}$ and $1 \mathrm{~N} \mathrm{NaOH}$ using $\mathrm{pH}$ electrode.

The sterilized flasks were inoculated with the same inoculums of the studied fungal species and incubated at $25^{\circ} \mathrm{C}$ for 7 days; after which, the mycelial dry weights and chitinase activity were determined.

\subsection{Effect of incubation temperature}

Flasks containing equal amounts of modified Czapek-Dox's broth media $(50 \mathrm{ml})$ containing $1.0 \%$ colloidal chitin as a carbon source was adjusted to $\mathrm{pH} 5.0$, sterilized, inoculated with a relatively equal numbers of the fungal spores and incubated at the following temperatures, 20, 23, 25, 27, 30, 35 and $40^{\circ} \mathrm{C}$. At the end of incubation period (7days), cultures were harvested for determining of the dry biomass.

\subsection{Determination of mycelial dry weight}

At the end of the fermentation process, the culture flasks were filtered through preweighted whatman No.1 filter papers.

The filter papers were washed twice with distilled water to remove non digested chitin, dried in an electric oven at $70^{\circ} \mathrm{C}$ and left in desiccators to attain room temperature.

The filter papers were then weighted at regular intervals till the two successive weights were the same [17].

\subsection{Estimation of chitinase activity}

The release of reducing sugar $(N-$ acetylglucosamine) from chitin substrate was used as the standard method for the assay of enzyme activity [18]. 


\subsubsection{Preparation of the crude chitinase}

At the end of incubation time, cell-free cultures filtrates were centrifuged at $5000 \mathrm{rpm}$ for 20 minutes in a cooling centrifuge. The clear supernatant was considered as the source of crude chitinase [19].

\subsubsection{Assay of chitinase activity}

The chitinase assay was carried out [18] with some modifications ${ }^{(\mathbf{1 4} \& 19) .}$ The enzyme reaction mixture containing $1 \mathrm{ml}$ of crude enzyme preparation and $1 \mathrm{ml}$ of $1 \%$ colloidal chitin in citrate-phosphate buffer ( $\mathrm{pH}$ 5.0) was incubated at $50^{\circ} \mathrm{C}$ for one hour.

The amount of $\mathrm{N}$-acetylglucosamine of the enzyme reaction mixture was then determined [20].

Estimation of $N$-acetylglucosamine was carried out as follow Reagents

Potassium tetraborate: was prepared by adding the calculated amount of $\mathrm{KOH}$ to $\mathrm{H}_{3} \mathrm{BO}_{3}$ solution. The $\mathrm{pH}$ of the solution was 9.2 when diluted.

\section{$P$-Dimethyl-amino-benzaldehyde (DMAB) reagent}

10 gm of DMAB (Sigma) were dissolved in $100 \mathrm{ml}$ of analytical reagent glacial acetic acid which contain $12.5 \% \quad(\mathrm{w} / \mathrm{v}) \quad 10 \mathrm{~N} \quad \mathrm{HCl}$ (analytical reagent).

This reagent could be stored at $2.0^{\circ} \mathrm{C}$ for a month. Shortly before use it was diluted with 9 volume of reagent grade glacial acetic acid.

\section{Assay procedure}

The released of $N$-acetylglucosamine in reaction mixture was determined as follows: 0.1 $\mathrm{ml}$ of potassium tetraborate was added to the reaction mixture. The tubes then heated in a vigorously boiling water bath for 3 minutes and cooled in tap water.

Three $\mathrm{ml}$ of DMAB reagent then added and immediately after mixing, the tubes are placed in a bath and the temperature adjusted at $36-38^{\circ} \mathrm{C}$. After 20 minutes, the reaction tubes are cooled in tap water. The intensity of the resulting color solution was measured at $585 \mathrm{~nm}$ using spectrocolorimeter. The chitinase activity was determined by inference from the standard curve of different $\mathrm{N}$-acetylgluco-samine concentrations.

\section{Chitinase unit}

One unit defined as the amount of enzyme protein in $1 \mathrm{ml}$ required to produce $1.0 \mu \mathrm{mol}$ of $\mathrm{N}$-acetylglucosamine in one hour at $50^{\circ} \mathrm{C}^{(\mathbf{1 8} \& 21)}$
4. Laboratory evaluation of the entomopathogenic activity of
Trichoderma asperelliodes on

Aphis craccivora

4.1 Culture of Aphid craccivora

4.1.1 Rearing of the insect

The proper conditions and diet for rearing laboratory culture of the bean aphid (Aphis craccivora) and maintenance of aphid colonies [23] Serial cultivation of cowpea plants in plastic pots (50 cm diameter in $25 \mathrm{~cm}$ highest) were prepared under the laboratory conditions. Samples of infested cowpea plants were collected from cowpea field, put in paper bags, and transferred to the laboratory.

The cowpea aphids were transferred from infested plants to non-infested cultivated ones by using fine brush.

Aphid colonies were away from any contamination by placing infested samples in cages covered with muslin cloth, which were proved to be advantageous to permit good ventilation and light penetration and avoid aphids from parasites and predators [23].

\subsubsection{Biological studies}

The objective of this experiment was to study the effect of feeding on some host plant leaves on biological aspects of A. craccivora under controlled conditions. Ten adult of A. craccivora were transferred from sensitive culture in the laboratory by hair brush to each leaf discs of bean $2 \mathrm{~cm}$ diameter and left for a period of 24 hours.

These discs were placed into pads of wet cotton in Petri-dishes. After 24 hours adults were removed and the discs with the nymphs. Fifty nymphs of the same age were individually transferred by mean of a camel hair brush to leaf discs of bean.

For conserving host plants leaf discs fresh, water moist cotton pad below the leaf disc equipped each Petri-dishes. Duration and development of alive stage were recorded.

All Petri-dishes were held at the same conditions of $27 \pm 2^{\circ} \mathrm{C}$ and relative humidity of $65 \pm 5 \%$ R.H [24].

\subsection{Fungal inoculation}

Spores of fungal isolate were harvested by rinsing with sterilized water containing $0.005 \%$ Tween 80 from 7 days old culture (Dox medium grown at $25 \pm 1^{\circ} \mathrm{C}$ for $\boldsymbol{T}$. asperelliodes isolate). The suspensions were filtered through cheesecloth to reduce mycelium clumping.

The spores were counted in the suspensions using a hemocytometer. The concentrations were adjusted to $10^{5}, 10^{6}, 10^{7}$ and $10^{8}$ spore $/ \mathrm{ml}$. 
4.3 Effect of spores suspension of $T$. asperelliodes on A. craccivora

The effect of the fungus on the infected leaves was studied at this experiment. Three replicates each consist of five leaves were used. Each leaf had fifty individuals of adult $A$. craccivora. Leaves were sprayed with two $\mathrm{ml}$ of different spores suspension of $T$. asperelliodes and the control was treated with two $\mathrm{mL}$ of sterilized water containing $0.005 \%$ tween 80 only. The treatments and control were incubated for 7days under laboratory conditions $\left(25 \pm 1^{\circ} \mathrm{C}, 65 \pm 5 \%\right.$ $\mathrm{RH}$ and $12 \mathrm{hr}$ photoperiod). Adult mortality was observed after $1,3,5$, and 7 days. $\mathrm{LC}_{50}$ and $\mathrm{LT}_{50}$ were calculated after 7 days [25].

\section{Examination of the treated Aphid insects} by scanning electron micro-scope (SEM)

The insects of Aphid (adult) were treated by the Trichoderma asperelliodes culture filtrate to indicate its effects on the cuticle of the insect, the growth of the fungus mycelium on the insect surface, and observe any other symptoms on the treated insects after 5 days.

The treated insects were examined by scanning electron microscope (SEM) (JEOLJSM $5500 \mathrm{LV}$ ) by using high vacuum mode at the Regional Center of Mycology and Biotechnology, (RCMB) Al-Azhar University. Cairo, Egypt.

\section{Examination using TEM}

Tissue specimens of the treated insects Aphid (adult) cuticle by the T. asperelliodes culture filtrate were prepared for TEM [22]. Stained sections were examined with a JEOL 1010 Transmission Electron Microscope at the Regional Center for Mycology and Biotechnology (RCMB) Al-Azhar University.Cairo, Egypt.

\section{Statistical analysis}

The obtained data were statistically analyzed using [26] statistical analysis software, Microcomputer program.

\section{Results and Discussion}

In this study the isolated fungal species from soil, seeds and insects were purified and identified using both morphologically by light microscope Fig (1\&2) and genetically by the $18 \mathrm{~S} r$ RNA gene of DNA methods as Trichoderma Asperelliodes Fig (1a, b\& c).

Effect of some environmental conditions on dry weight and the chitinase enzyme production by Trichoderma asperelliodes Effect of pH

The results of this study indicated that the maximum mycelial dry weight and crude chitinase enzyme production by Trichoderma asperelliodes had a peak of activity at $\mathrm{pH} 7.5$ Fig (2). Gradually decreasing in chitinase activity was clearly observed below or above $\mathrm{pH} 7.5$ to reach a minimum value at $\mathrm{pH} 5.5$ showing about $22.14 \%$ from the maximal activity obtained.

These finding are consistent with those previously reported $\left({ }^{27}\right)$, they found that suitable $\mathrm{pH}$ values for a favorable growth of Paecilomyces fomosoroseus were obtained in the range of $\mathrm{pH} 6$ to 9 . On the other hand, the optimum chitinase production and biomass yield by T. viride, Aspregillus carneus, , T. harzianum and $\mathrm{T}$. atroviride were reported at pH $5.0^{(19,28,29,30, ~ \& 31)}$, respectively. Other workers reported that most of the fungal chitinases showed optimum productivity close to $\mathrm{pH} 5.0$ [18, 32and 33].

\section{Effect of incubation temperature}

The obtained data revealed clearly that the optimum incubation temperature for maximum mycelial dry weight and crude chitinase enzyme production by $T$. asperelliodes was $30 \mathrm{C}^{\circ} \mathrm{Fig}$ (3). Increasing or decreasing the incubation temperature to 20 and $45 \mathrm{C}^{\circ}$ resulted in a great reduction in mycelial dry weight and a markedly loss in chitinase activity showing about $22.76 \%$ of that obtained at optimal reactions temperature.

The results were in accordance with those of $[31,34-36]$, who found that the optimum temperature for maximal chitinase productivity of T. harzianum was $30^{\circ} \mathrm{C}$. The same temperature was also reported as optimal for maximal chitinase production under control conditions by other investigators [19, 28, 32 \&37].

On the other hand, it was indicated that the optimum incubation temperature for optimal production of chitinase enzyme by A. fumigates was $35^{\circ} \mathrm{C}{ }^{(\mathbf{1 8 )})}$ While, $25^{\circ} \mathrm{C}$ was recorded as the optimum incubation temperature for $\mathrm{T}$. harzianum and $\mathrm{P}$. fumosorosea [38 \& 39], respectively.

Pathogenicity effect of spore's suspension of T. asperelliodes on A. craccivora

In this study, the efficiency of $T$. asperelliodes spores suspension was tested against aphid adults by applying different concentrations of spores $\left(10^{5}-10^{8}\right.$ spore $\left./ \mathrm{mL}\right)$ at the laboratory conditions Table (1).

Mortality percentages after 7 days of application were ranged between 30.0 to $88 \%$ and $\mathrm{LC}_{50}$ value was $5.4 \times 10^{7}$ spore $/ \mathrm{ml}$ and $\mathrm{LT}_{50}$ value was 5.1 days. Previous study showed that different conidial concentrations of Paecilomyces fumosorosea $\left(10^{5}-10^{8}\right.$ spore $\left./ \mathrm{mL}\right)$ 
against larva of Planococcus citri and mortality percentages after 7 days of application were ranged between 36.0 to $60 \%$ [39].

It was also indicated that the nematode infection was significantly decreased compared to control by using different conidial
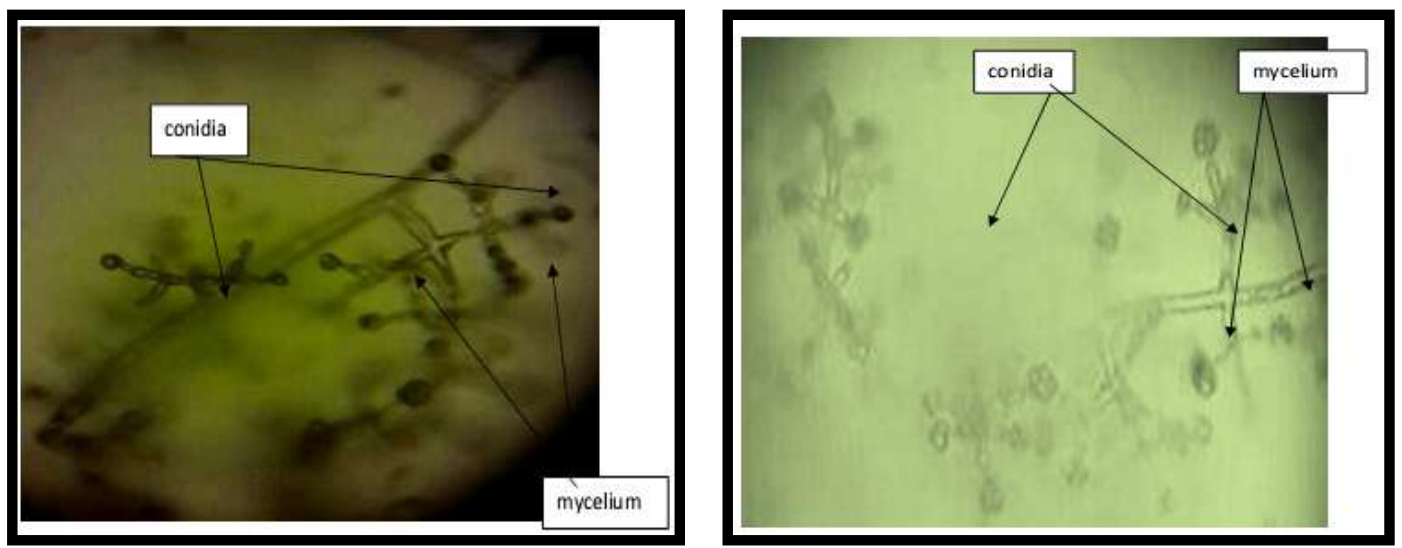

Fig $(1,2)$ Trichoderma asperelloides under light microscope.

CTTATTGGGGACGCGGAGGGACATTACCGAGTTTACAACATCCCAAACCCAATGTGAACGTT ACCAAACTGTTGCCTCGGCGGGGTCACGCCCCGGGTGCGTCGCAGCCCCGGAACCAGGCGCC CGCCGGAGGAACCAACCAAACTCTTTCTGTAGTCCCCTCGCGGACGTATTTCTTACAsGCTCT GAGCAAAAATTCAAAATGAATCAAAACTTTCAACAACGGATCTCTTGGTTCTGGCATCGATG AAGAACGCAGCGAAATGCGATAAGTAATGTGAATTGCAGAATTCAGTGAATCATCGAATCTT TGAACGCACATTGCGCCCGCCAGTATTCTGGCGGGCATGCCTGTCCGAGCGTCATTTCAACCC TCGAACCCCTCCGGGGGATCGGCGTTGGGGATCGGGACCCCTCACACGGGTGCCGGCCCCAA AATACAGTGGCGGTCTCGCCGCACCCTCTCCTGCGCAGTATTTTGA.

Fig (1a) Large subunit partial sequence of 18S rRNA gene of DNA

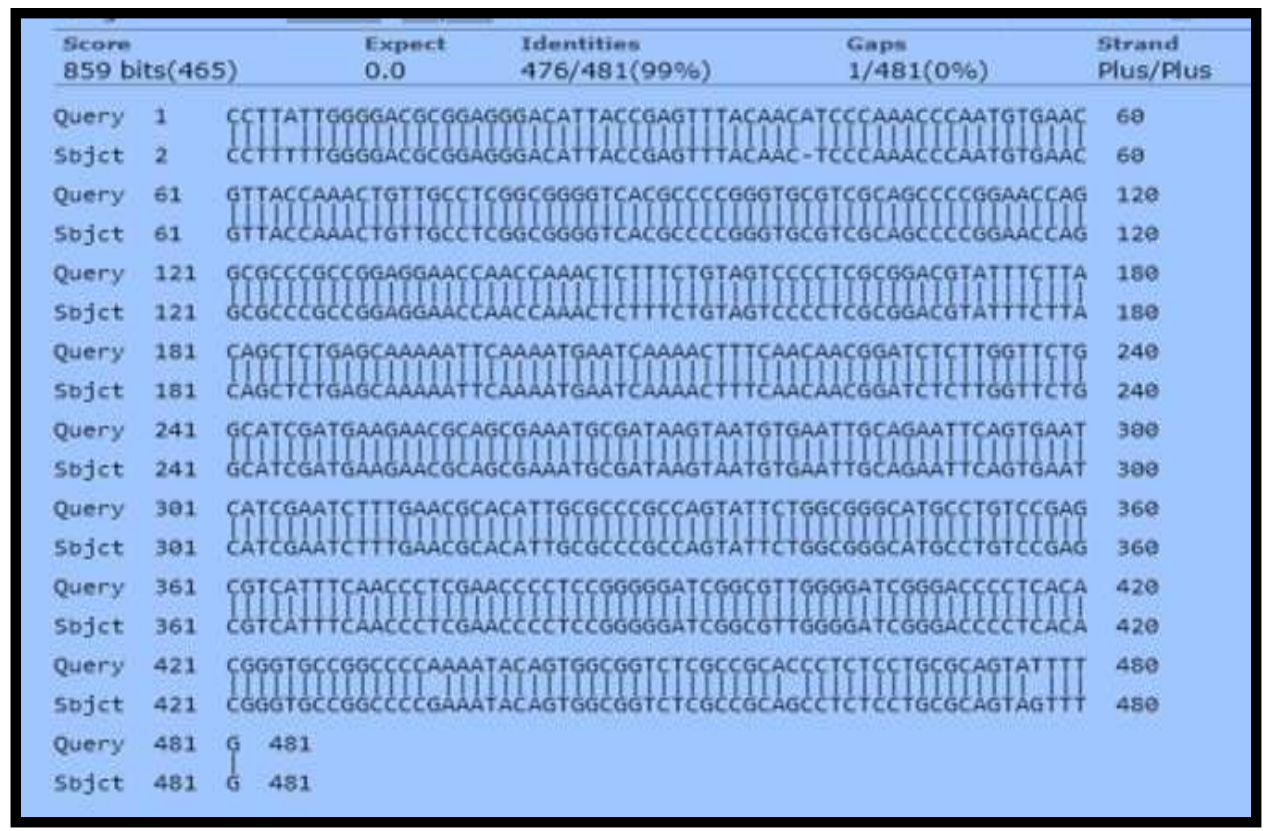

Fig (1b) 18S ribosomal RNA gene, partial sequence; internal transcribed spacer1 and 5.8S ribosomal RNA gene, complete sequence; and internal transcribed spacer 2, partial sequence. 


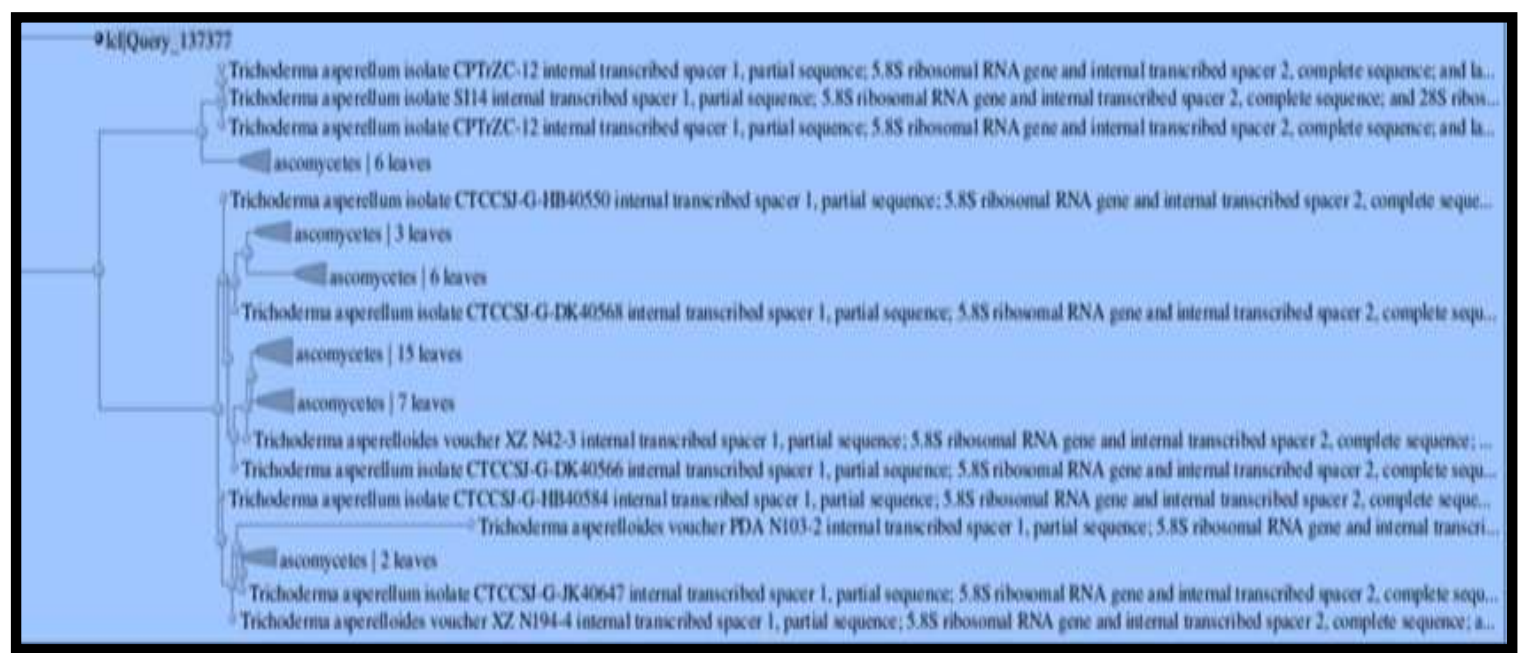

Fig (1c) Phylogenetic dendrogram of different fungal strains accessions to isolate (T.asperelloides) revealed by average linkage cluster analysis based on 18S rRNA partial sequence (similarity 99 $\%)$.

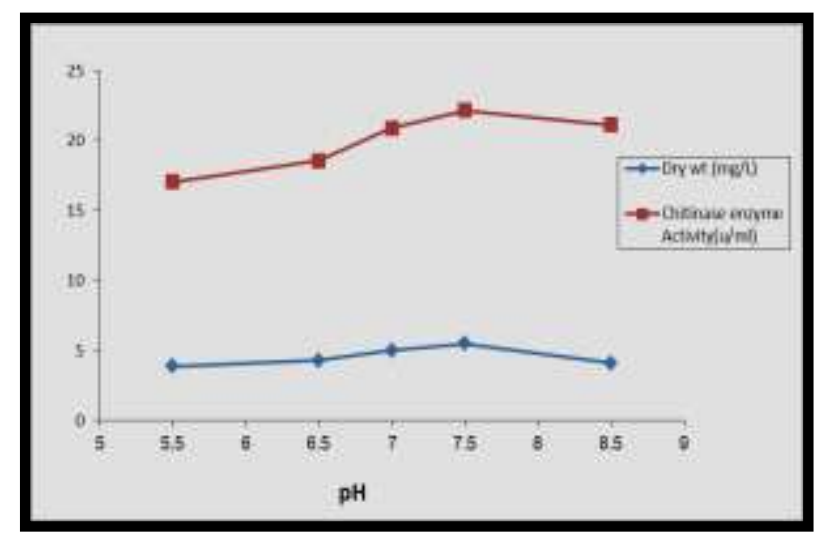

Fig (2) Effect of different $\mathrm{pH}$ values on mycelia dry weight and chitinase enzyme production by Trichoderma asperelliodes.

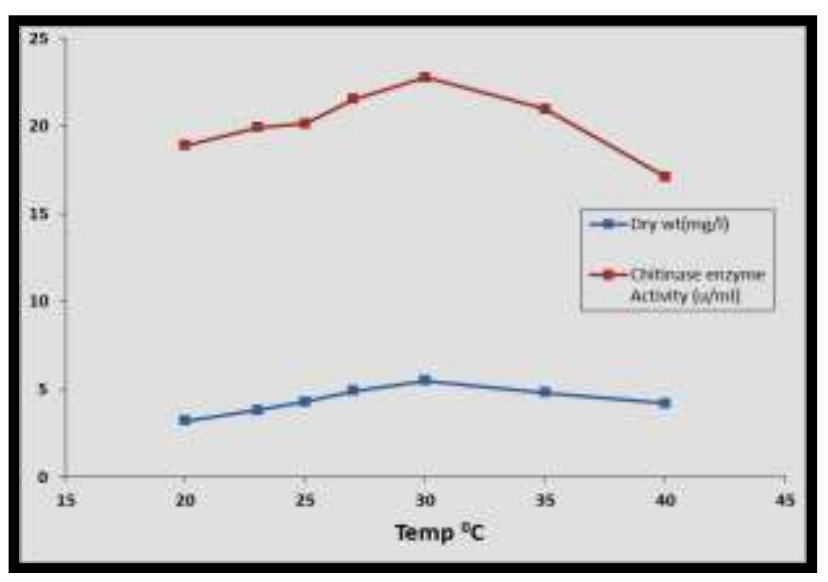

Fig (3) Effect of different incubation temperatures on mycelia dry weight and chitinase enzyme production by Trichoderma asperelliodes. 
Table (1) Mortality percentages of adult Aphis crassivora after application with different concentrations of T. asperelliodes spores suspension under laboratory conditions.

\begin{tabular}{|c|c|c|c|c|c|c|c|c|c|c|c|c|}
\hline \multirow{3}{*}{$\begin{array}{c}\text { Concentration } \\
\text { (Spores/mL) }\end{array}$} & \multicolumn{12}{|c|}{ Mortality percentages of adult of Aphid crassivora per 50 individuals } \\
\hline & \multicolumn{3}{|c|}{ After 1 day } & \multicolumn{3}{|c|}{ After 3 days } & \multicolumn{3}{|c|}{ After 5 days } & \multicolumn{3}{|c|}{ After 7 days } \\
\hline & Life & Dead & $\begin{array}{l}\text { Mort } \\
\text { ality } \\
(\%)\end{array}$ & Life & Dead & $\begin{array}{l}\text { Mort } \\
\text { ality } \\
(\%)\end{array}$ & Life & Dead & $\begin{array}{l}\text { Mort } \\
\text { ality } \\
(\%)\end{array}$ & Life & Dead & $\begin{array}{l}\text { Mort } \\
\text { ality } \\
(\%)\end{array}$ \\
\hline $6 \times 10^{5}$ & 45 & 5 & 10 & 43 & 7 & 14 & 40 & 10 & 20 & 35 & 15 & 30 \\
\hline $6 \times 10^{6}$ & 42 & 9 & 18 & 35 & 25 & 30 & 29 & 21 & 42 & 23 & 27 & 48 \\
\hline $6 \times 10^{7}$ & 32 & 18 & 36 & 26 & 24 & 49 & 22 & 28 & 56 & 16 & 34 & 68 \\
\hline $6 \times 10^{8}$ & 22 & 28 & 59 & 15 & 35 & 70 & 11 & 39 & 78 & 6 & 44 & 88 \\
\hline
\end{tabular}

\section{SEM and TEM examination}

In this study, $T$. asperelliodes spores suspension efficiency was tested against aphid adults. Treated aphids were examined by (SEM and TEM).

The results of SEM examination showed the aggregation of $\mathrm{T}$. asperelliodes conidia Fig ( $3 \& 4)$ and mycelium Fig (5\&6) on the surface of aphids. In addition, rupture of cuticle layer was clear in Fig (7). The growth of the fungus on the cuticle of the infected insects and hyphae penetration into insect cuticle as well as proliferation of cuticle were also appeared [43].

In addition, the collection of conidia and mycelium of Beauvaria basiana on the surface of Tropionota squalid (adult) was shown in other study [44].

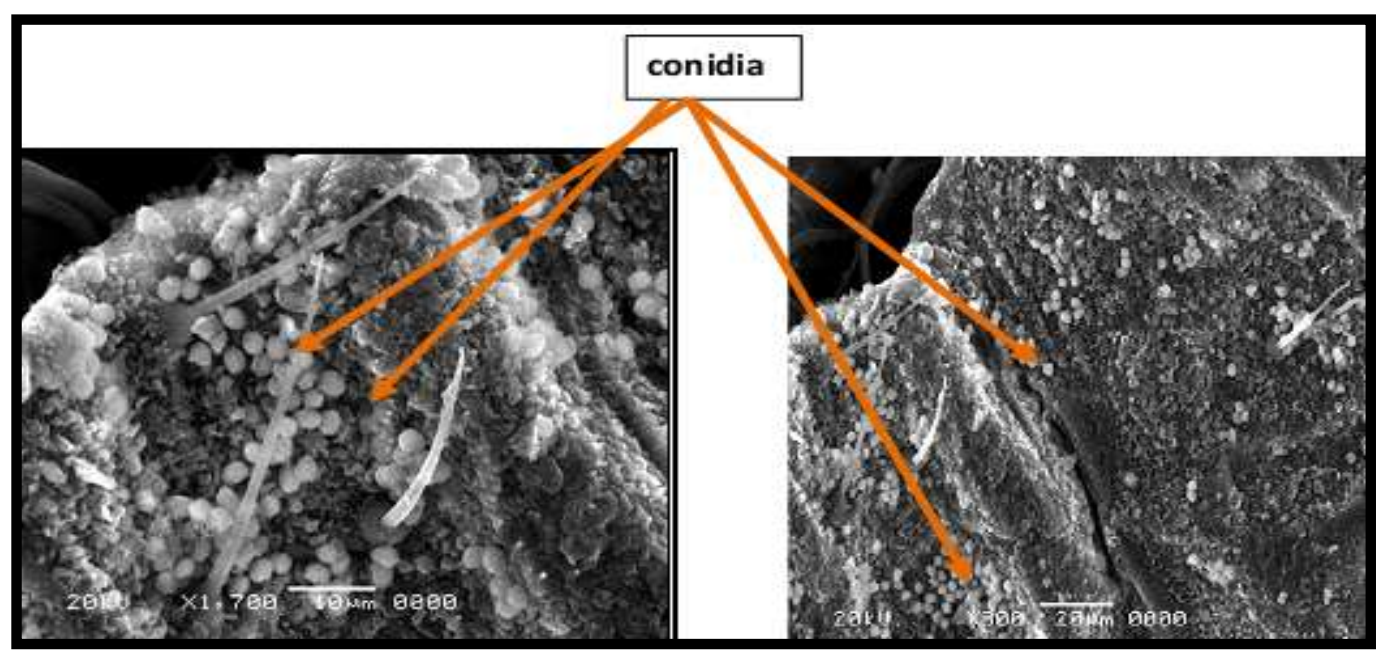

Fig $(3,4)$ Conidia of T. asperelliodes on the surface of aphid insects under (SEM)

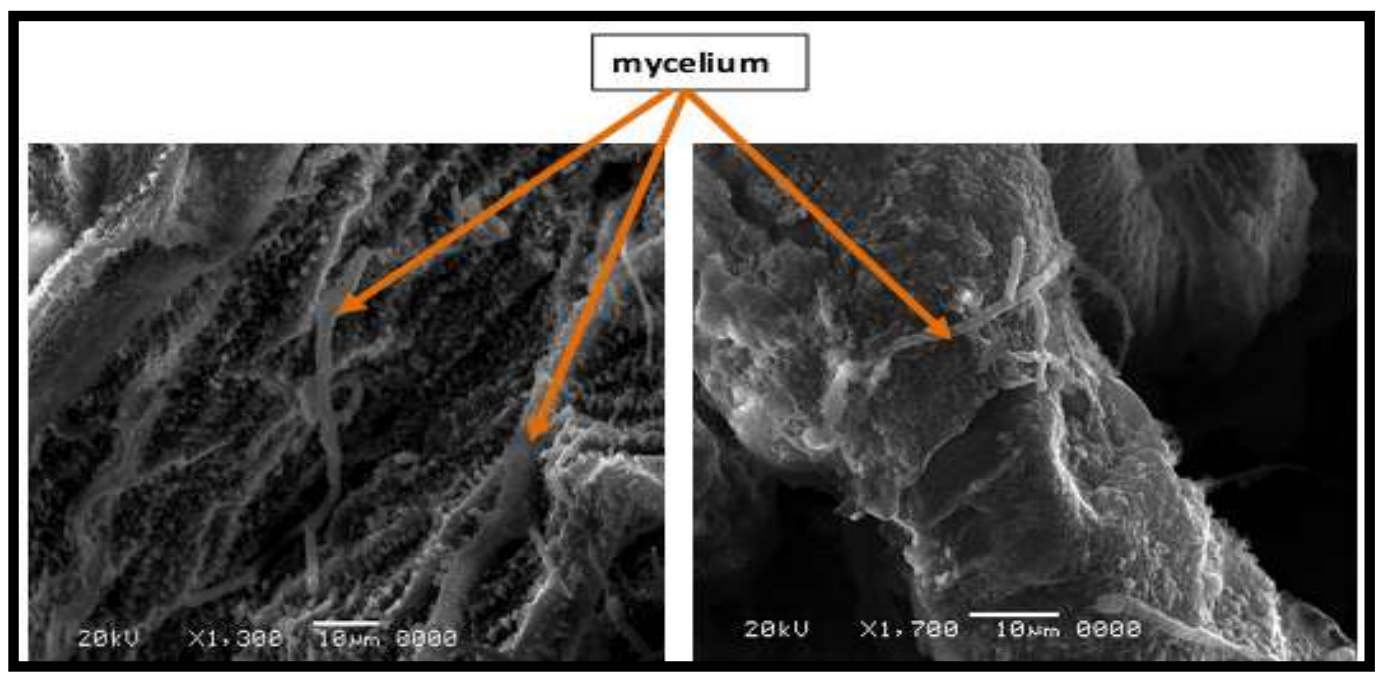

Fig $(5,6)$ Mycelium of T. asperelliodes on the surface of Aphid insec 


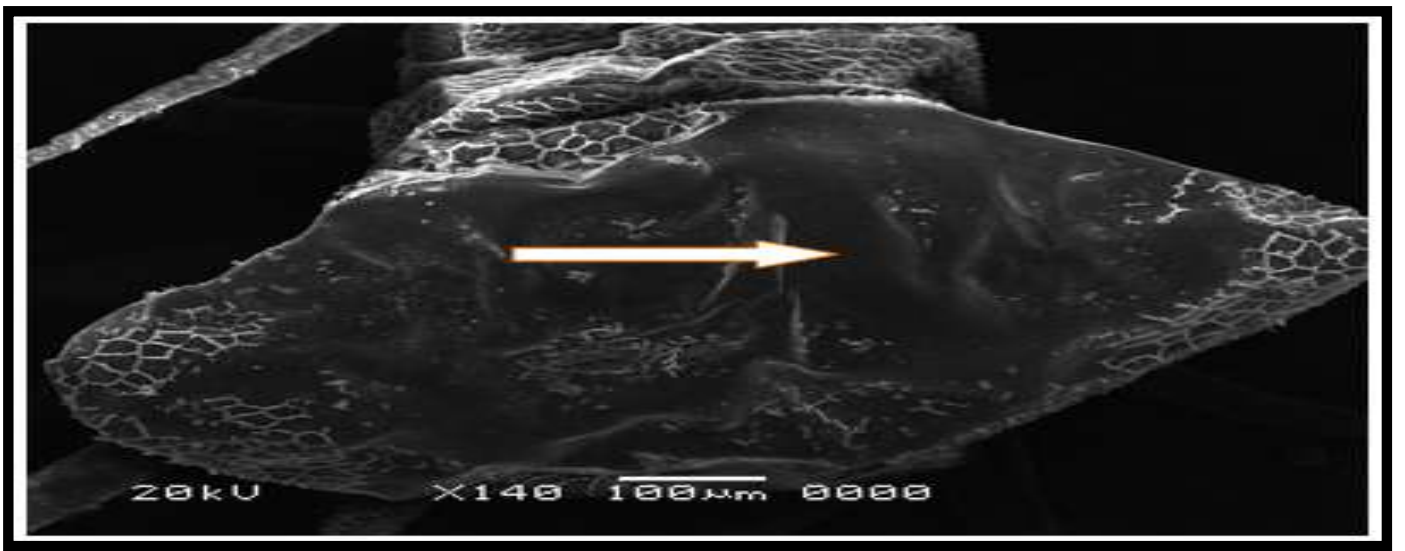

Fig (7) Rupture in cuticle layer of Aphids insect (SEM) as arrow show

Also, TEM examination proved the invasion and penetration of $\mathrm{T}$. asperelliodes conidia into the tissue of aphid insects and leaving fungal spores on the surface Fig (8). The conidia of $\mathrm{T}$. asperelliodes on the tissue of aphid insects was also clear Fig (9).

Finally the cells of treated aphid insects with T. asperelliodes spores suspension were ruptured due to growth of the fungus inside the insect cells Fig (10).

In previous studies [43 \& 45] the examination by electron microscopy of adults of Aphis gossypii insects treated by Trichoderma hamatum revealed that the spore suspension brought about massive disintegration and

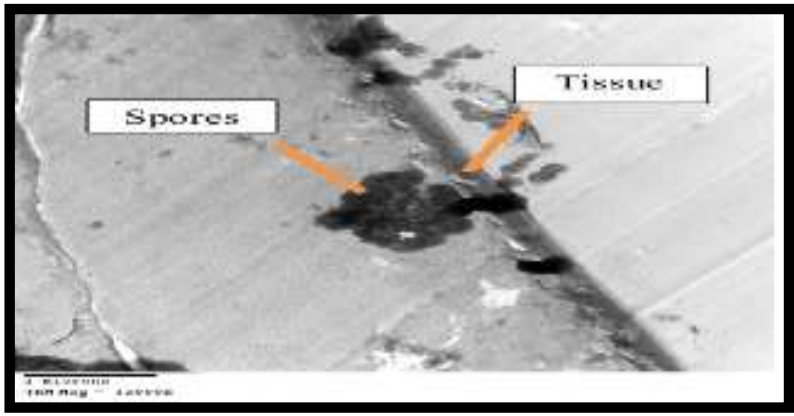

Fig(8) Invasion on the tissue with spreading fungle spores (TEM). deformation of the aphid's body and tissues ended by the development and the colonization of the fungus inside the insect.

It was reported that the cell organelles of cotton leaf worm, Spodoptera littoralis have become malformed and lost their integrity due to the bacterial infection, while the viral infection has caused many cell organelles to disappear and has induced the marker of cell death [46].

The process of colonization was also shown in the pupae of Rhammatocerus schistocercoides and Diatraea saccharalis treated with Metarhizium flavoviride and $\mathrm{M}$. anisopliae [47, 48], respectively.

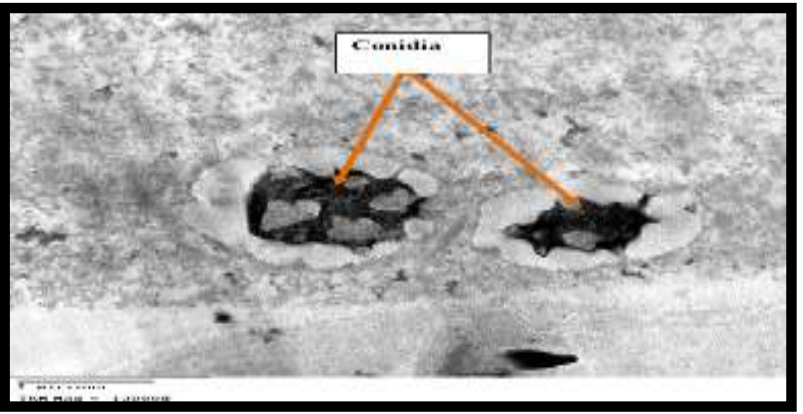

Fig (9) Conidia of T. asperelliodes on the cells of Aphid insect and rupture of the cells (TEM).

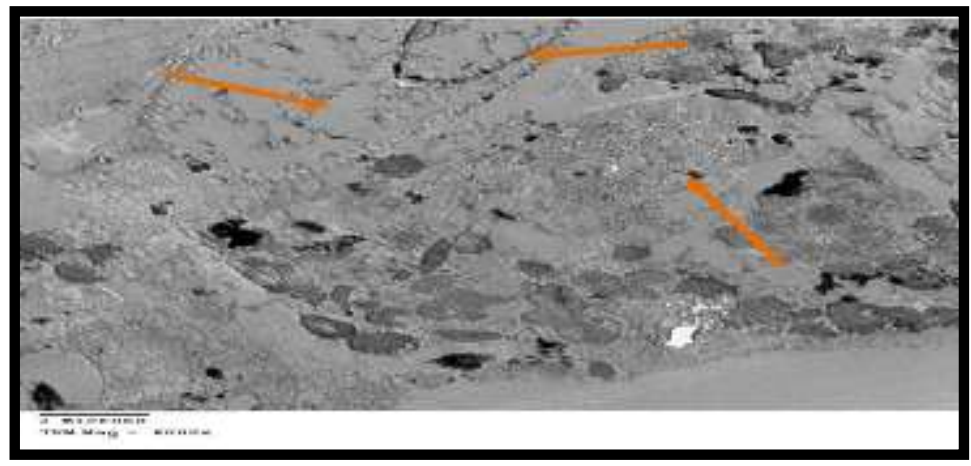

Fig (10) Rupture in the cells of Aphids (TEM) as arrow show 


\section{References}

[1] V.H.F.Emden, R .Harrington, Aphids as crop pests. CABI Publishing, London, Nosworthy Way, Walling ford, Oxfordshire OX108DE, U, , p.717, 2007

[2] N.J.Armes, D. R.Jadhav, G.S.Bond A.B.S. King, Insecticide resistance in Helicoverpa armigera in South India. Pestic. Sci.,Vol.34, pp .355-364, 1992.

[3] M.J.Brewer, J.T.Trumble , Beet-armyworm resistance to fenvalerate and methomylresistance variation and insecticide synergism, J. Agri. Entomol, Vol.11, PP.291-300, 1994

[4] A.Abdel-Halim, S.M.Soliman, H.A.Barrania, Field evaluation of two biocides for bollworms control. Egypt. J. Appl. Sci., Vol.17 (11), PP. 279-290, 2002

[5] A.I Abd EL-Kareim, S.A. Moustafa, I.M. Shanab, N.M. Ghanim, Evaluation the role of some parasitoids in biological control of the pink and spiny bollworms in cotton fields. J. Agric.Sci. Mansoura Uni, Vol.3(9), PP.6811-6821, 2008.

[6] G.A.Zhang, L.B.Zong, H.H.Duan, J.H.Xiong, R.Y.Lu, F.L.Xu, Spatial distribution of the flower bug, Orius similis, and its interaction with the pink bollworm, Pectinophra gossypiella in cotton fields. Intern. J. Pest Managem, Vol. 40(4), PP.309-312, 1994.

[7] S.A.Mahfouz, A.A.Abou El-Ela, Biological control of pink bollworm Pectinophra gossypiella (Saunders).Microb and Biochem Technol, Vol. (2), PP.30-32.

[8] D.Margalit, J.Dean, (1982): The story of Bacillus thuringeinsis Var. israelensis (Bti). J. Am. Mosq., Cont. AQssoc, Vol. 1, PP. 1-7, 2011.

[9] V.Fourmier, J.Brodeur, Dose-response susceptibility of pest aphids (Homptera: Aphididae) and their control on hydroponically grown Lettuce with the Entomopathogenic fungus Verticillium lecanii, Azadira chitin, and Insecticidal soap. Environ. Entomol,Vol. 29 (3), PP. 568-578, 2000.

[10] G.H.Sewify, Neozygites fresenii causing epizootic in aphids (Aphis craccivora Koch.) population on faba bean in Egypt. Bull Fac. Agric, Univ. Cairo., Vol, 51(1), PP. 85-94., 2000.

[11] E.M.A El-Sayed, Biological control of pink boll worm pectinophra gossypiell by degrading enzymes produced from some microorganisms. ph.D. Thesis, Botany department, Fac. Sci , Zagazig Univ., Egypt., 2014 .
[12] L.E.Johnson, E.A.Curl, J.H.Bond, H.A.Fribourg, Methods for studying soil microflora-plant diseases relationship. Burgess Publ. Co. Minn. USA, 1959.

[13] M.S.Goettel, G.D.Inglis, Hyphomycetes, in: Manual of techniques in insect pathology. Academic Press. USA. ISBN Vol. 6, pp . 214-226,1997.

[14] E.M.A.El-Sayed, Studies on insect cuticledegrading enzymes by some microorganisms and their role in biocontrol on insects, M. Sc. Thesis. Fac. Sci., Zagazig Univ., Egypt, 2008 .

[15] A.H.Abdel-Salam, Natural incidence of Cladosporium sPP. as a bio-control agent against white flies and Aphids in Egypt.J. Appl. Entomol., Vol.127(4), PP.228-235 , 2003.

[16] D. Smith, A.H.S.Onions, The preservation and maintenance of living fungi. Commonwealth Mycology Inst, Kew UK, p. 51,1983 .

[17] A.S.A.El-Sayed, Studies on some thermophilic chitin degrading fungi. M.Sc. Thesis, Fac. Sci, Zagazig Univ., Egypt, 2005

[18] J.Monreal, E.T.Reese, The chitinase of Serratia marscencs. Can. J. Microbiol., Vol. 15, PP. 689-696, 1969.

[19] A.A.Shindia, Chitinase production by some thermotolerant and thermophlic fungi isolated from compost. Egypt. J. Microbiol, Vol.36, PP.39- 57, 2001.

[20] J.L.Reissig, J.L.Strominger, L.F.Leloir, A modified colorimetric method for estimation of $\mathrm{N}$ - acetyleglucoseamine sugars. J. Biol. Chem.,Vol.27 , PP.959966,1955 .

[21] K.E.M.Shalaby, Physiological Studies on some chitin degrading fungi. M.Sc. Thesis, Fac. Sci, Zagazig Univ, Egypt, 1999 .

[22] J.J.Bozzola, L.D.Russell, Electron Microscopy,Second Edition. Sudbury, MA: Jones and Bartlett Publishers, 1999.

[23] R.M.El-Gendy, Insecticidal activity of some pesticides against cowpea aphid, Aphis craccivora (Koch) (Aphididae: Homoptera. M.Sc. Thesis, Fac. Of Sci., Zagazig Univ., PP.220, 2009.

[24] W.Ebeling , Testingacaricides. In: Harol H. Shepard (ed.) .Methods of testing chemicals and insects. Burges Publishing Co., Minneapolis. Vol. II, PP. 156- 192 , 1960.

[25] D.I.Finny, Propit analysis $3^{\text {rd }}$ ed. Cambrige Univ. Press, London, 1971.

[26] Costat Statistically Software Microcomputer program Analysis. Version 6.311. CoHort 
Software, Monterey, California, USA ,2005.

[27] S.M.Shim, K..R.Lee, S.H.Kim, J.W.Kim, U.Y.Lee, J.O.Shim, M.W.Lee, T.S.Lee, The optimal culture condition affecting the mycelial growth and fruiting body formation of Paecilomyces fumosoroseus. Kor. J. Mycol.,Vol. 31(4) , PP. 214- 220 , 2003 .

[28] A. A.Sherief, M.M.El Sawah, M. A.AbdelNaby, Some properties of some chitinase produced by a potent Aspergillus carneus strain. Appl. Microbiol. And Biotechnol., Vol.35 , PP. 228- 230,1991 .

[29] A.Kapat, S.K.Roskshit, T.Panda, Optimization of carbon and nitrogen sources in the medium and environmental factors for enhanced production of chitinase by Trichoderma harzianum. Bioprocess Engineering,Vol.15 ,PP.13-20, 1996a .

[30] I.A.Hoell, S.S.Klemsedal, G.VaajeKolstad, S.J.Horn, V.G.H.Eijsink, Over expression and characterization of a novel chitinase from Trichoderma atroviridie strain P1.Biochim. Biophys. ACTA, Vol.1 , PP.522-529, 2005.

[31] E.M.Ghareeb, Physiological studies on some chitinolytic fungi and their role in control of seeds insects. M.Sc. Thesis, Fac. Sci, Zagazig Univ., Egypt, 2009.

[32]Y.Elad, I.Chet, Y.Henis, Degradation of plant pathogenic fungi by Trichoderma harzianum. Can. J. of Microbiol.,Vol. 28 , PP.719-725, 1982 .

[33] P.Patidar, D.Agrawal, T.Banerjee, Optimisation of process parameters for chitinase production by soil isolates of Penicillium chrysogenum under solid substrate fermentation. Proc. Biochem,Vol. 40 (9), PP. 2962-2967, 2005 .

[34] A.Kapat, S.K.Rakshit, T.Panda, Parameters optimization of chitin hydrolysis by Trichoderma harzianum chitinase under assay conditions. Bioprocess Engineering,Vol. 14 (5) PP.270-274, 1996b.

[35] N.H.E.M.Lokma, Studies on some Egyptian fungi and their relationship with piercing sucking pests M. Sc. Thesis. Fac. Sci, ZagazigUni, Egypt, 2010 .

[36] K.M.Nampoothiri, T.V. Baiju, C. Sandhya, Process optimization for antifungal chitinase production by Trichoderma harzianum. Proc. Biochem., Vol. 39 , PP. 1583- 1590,2004

[37] M.A.El-Naghy, S.K.M.Hassan, A.M.Elshahed, Chitin digestion by some soil fungi. Bull. Fac. Sci., Assiut Univ., Vol.14(1), PP. 33-47, 1985.

[38] J.Shakeri, H.A.Foster, Proteolytic activity and antibiotic production by Trichoderma harazianum in relation to pathogenicity to insects. Enzyme and Microbiol. Technol.,Vol.40(4) ,PP. 961-968, 2007

[39] R.M.H.Hussien, isolation, identification and efficiency of entomopathogenic fungi associated with some species of scale insects and mealbugs in east delta region. Msc. Science, Fac. Sci, Zagazig Uni , 2015 .

[40] N.Sahebani, N.Hadavi, Biological Control of the Root-Knot Nematode Meloidogyne Javanica By Trichoderma harzianum. Soil Bio .and Biochem,Vol.40, PP.20162020, 2008.

[41] C.Panyasiri, T.Attathom, H.M.Poehling, Pathogenicity of entomopathogenic fungi - Potential candidates to control insect pests on tomato under protected cultivation in Thailand. J. Plant Disease and Protect, Vol. 114, PP. 278- 287, 2007

[42] F.Demirci, M.Mustu, M.B.Kaydan, Laboratory evaluation of the effectiveness of the entomopathogen Isariafarinosa on citrus mealy bug, Planococcus citri. J. Pest Sci.,Vol.84, PP.337- 342, 2011.

[43] A.Gabarty, H.M.Salem, M.A.Fouda, A.A.Abas, A.A.Ibrahim, Pathogencity induced by the entomopathogenic fungi Beauveria bassiana and Metarhizium anisopliae in Agrotisipsilon (Hufn.). J. Radiation Res. and Appl. Sci, Vol.7 (Issue 1) ,PP. 95-100 , 2014 .

[44] M.A.AbdEl-Kader, Usage of fungus Beauveria bassiana in the control of Tropinota squalida, Sesamia cretica and Cassida vittata at Sharkia Governorate, Ph.D Thesis, Botany Department, Fac. Sci, Zagazig University, PP. 238, 2016.

[45] N.H.E.M.Lokma, Evaluation of some fungal metabolites as alternatives pesticides in control Aphis gossypii Ph.D. Thesis, Botany Dept, Fac. Sci, Zagazig Uni, Egypt, 2017.

[46] A.A.El-Banna, S.M.I.Abd El-Kareem, A.S. El-Akad, M.A.Hussein, A.R.Fahmy, H.K. Bekheit, Histopathological effects of a mixture of two bioagents on the larval midgut of the cotton leaf worm, Spodoptera littoralis(Boisd.), Egypt. Acad. J. Biolog. Sci., Vol. 3 (1), PP.2735,2012 .

[47] S.Vestergaard, T.M.Butt, A.T.Gillespie, J. Eilenberg, Light and electron microscopy studies of the infection of the western flower thrips Frankliniellaoccidentalis 
(Thysanoptera: Thripidae) by the entomopathogenic fungus Metarhizium anisopliae. J. Invertebr. Pathol., Vol. 73, PP. 25-33, 1999 .

[48] L.C.L.Schneider, C.V.Silva, J.A. Pamphile, H. Conte, Infection, colonization and extrusion of Metarhizium anisopliae (Metsch) Sorokin (Deuteromycotina: Hyphomycetes) in pupae of Diatraeasaccharalis F. (Lepidoptera: Crambidae). J. Entomol .and Nematol., Vol. 5(1), PP.1-9, 2013. 